\title{
Effect on clinical outcome of breast feeding during acute diarrhoea
}

\author{
KHIN-MAUNG-U， NYUNT-NYUNT-WAI， MYO-KHIN， MU-MU-KHIN，TIN-U，THANE-TOE
}

\begin{abstract}
The effects of oral rehydration fluid alone and of oral rehydration fluid plus breast feeding on the course and outcome of acute diarrhoea were assessed in two groups of 26 children aged under 2 years. Children who continued to be breast fed during treatment with oral rehydration solutions passed significantly fewer diarrhoeal stools. They also passed, on average, a smaller volume of diarrhoeal stools and recovered from diarrhoea sooner after the start of treatment. Their requirement for oral rehydration fluid was significantly reduced.

Breast feeding exerts a beneficial effect on the course and outcome of acute diarrhoea by reducing the number and volume of diarrhoeal stools.
\end{abstract}

\section{Introduction}

Breast feeding has been advocated in many field and oral rehydration therapy projects; mothers are encouraged to continue breast feeding their child during diarrhoea by the World Health Organisation and other international organisations. ${ }^{12}$ The prevailing practice and belief by mothers and doctors alike is, however, that feeding a child with diarrhoea makes the condition worse. This is not unfounded as an early clinical trial in 1948 comparing feeding a milk formula with fasting during diarrhoea showed an increase in the volume and

Clinical Research Division, Department of Medical Research, Ministry of Health, Rangoon, Burma

KHIN-MAUNG-U, MMEDSCI, MACP, head of division and consultant physician

NYUNT-NYUNT-WAI, DCH, MMEDSCI, senior research officer and paediatrician

MYO-KHIN, MB, BS, research officer

THANE-TOE, MB, PHD, deputy director

Infectious Diseases Hospital, Rangoon, Burma

MU-MU-KHIN, MB, DCH, assistant paediatrician

TIN-U, MB, DTM\&H, medical superintendent

Correspondence to: Dr Khin-Maung-U. frequency of diarrhoeal stools (which, being obvious to mothers, makes them think milk feeding exacerbates diarrhoea) yet a beneficial result for the child because of a net retention of nutrients (which is not apparent to mothers). ${ }^{3}{ }^{4}$ Recent clinical trials of different milk formulas during acute diarrhoea showed that feeding milk formula during diarrhoea did not make the clinical outcome from diarrhoea worse. ${ }^{56}$

No controlled clinical trial to compare breast feeding with oral rehydration solution alone during the early acute phase of diarrhoea has previously been reported, so data on the effect of breast feeding during diarrhoea are still lacking. The aim of this study was to compare the effect on the clinical outcome from acute diarrhoea in children aged under 2 years of oral rehydration solution alone and breast feeding plus oral rehydration solution during the early stage of acute diarrhoea.

\section{Patients and methods}

We studied children aged 6-24 months admitted to the paediatric wards of the Infectious Diseases Hospital for acute watery diarrhoea of less than 48 hours' duration with grade II (moderate or severe) dehydration, ${ }^{12}$ who had been normally breast fed. Children with a concomitant illness (such as bronchopneumonia, urinary tract infection, clinically evident malnutrition, or shock), bottle fed children, and children who had received antibiotics before admission to hospital were not included in the study. Every child underwent physical examination, and in each case a relevant history was taken. Initial body weight $(\mathrm{kg})$ was taken on admission before starting rehydration treatment. Informed consent from the child's parent or parents was obtained in every case.

Each child entered into the study was allocated by random numbers to receive either oral rehydration solution alone or breast feeding plus oral rehydration solution. Children requiring intravenous treatment were given initial intravenous rehydration until a state of hydration (absence of clinical evidence of dehydration) had been reached (usually within about four hours after admission to hospital); thereafter these children were randomly allocated to receive either of the above regimens. None of these children was given tetracycline or any other antibiotic. Blood for packed cell volume, specific gravity, and assessment of plasma protein, sodium, potassium, chloride, and bicarbonate concentrations was taken from the patients on admission and every morning till discharge from the study. Amounts and types of fluids given by mouth and intravenously were recorded together with outputs of stools, urine, and vomitus every hour and body weights 
every six hours. On admission stool swabs were taken for culture of Vibrio cholera.

Ethical considerations were emphasised at all phases of the clinical trial. In most instances mothers tended to adhere to old beliefs and preferred to withhold breast feeding during the early acute phase of diarrhoea. Mothers of children allocated to receive oral rehydration solution alone were allowed to continue their practice for up to 24 hours; thereafter they were requested to resume breast feeding their children. Mothers whose children were allocated to receive breast feeding plus oral rehydration solution were told that no worsening of diarrhoea would occur with continued breast feeding during the early acute phase of diarrhoea and were requested to breast feed their children during the first 24 hours and to continue to do so thereafter. All mothers were assured of their prerogative to withdraw from the clinical trial at any time.

\section{STATISTICAL METHODS}

Correct trial size was calculated using data from previous studies according to variable of response used:

Purging volume-For children having a total purging volume of $90 \mathrm{ml} / \mathrm{kg} /$ patient, with a standard deviation of $50 \mathrm{ml} / \mathrm{kg} /$ patient, assuming that for breast feeding to produce a clinically significant deleterious or beneficial effect, it should produce an increase or a reduction in total purging volume by $50 \%$, for a significant $p$ value at 0.05 level and a power of $90 \%$-that is, $\beta$ or type II error of $0.10-$ the trial size for each treatment group was calculated to be 26 patients.

Number of diarrhoeal stools-For children producing a mean of 20 diarrhoeal stools per episode, with a standard deviation of seven per episode, assuming that for breast feeding to produce a clinically significant deleterious or beneficial effect, it should produce an increase or a reduction in the number of motions by one third, for a significant $\mathrm{p}$ value at 0.05 level and a power of $90 \%$ the trial size for each treatment group was calculated to be 23 patients.

Thus, to comply with both calculations, 26 patients were entered into each treatment group, each patient being allocated by random numbers. Results in the two treatment groups were compared using Student's $t$ test.

\section{Results}

Table I shows that children in the two treatment groups were comparable.

Children who were breast fed had, on average, five fewer motions $(p<0.05)$ than those who were not breast fed (table II). They also produced an average of about $250 \mathrm{ml}$ less of diarrhoeal stools and suffered diarrhoea in hospital for two hours less than children who were not breast fed during the first 24 hours (differences not significant). In addition, breast fed children required $550 \mathrm{ml}$ less oral rehydration solution (a reduction of $25 \%)(p<0.02)$ than those not breast fed during the early acute phase of diarrhoea.

The figure shows that during the initial 24 hours breast fed children produced obviously smaller volumes of diarrhoeal stools per $\mathrm{kg}$ body weight per six hour period than children who were not breast fed during the early phase of diarrhoea. In the second 24 hours, when both groups of children were breast fed in addition to receiving oral rehydration treatment, similar patterns of volumes of purging per kg per six hour period were observed.

TABLE I-Clinical characteristics of children receiving either oral rehydration solution (ORS) alone or ORS plus breast feeding

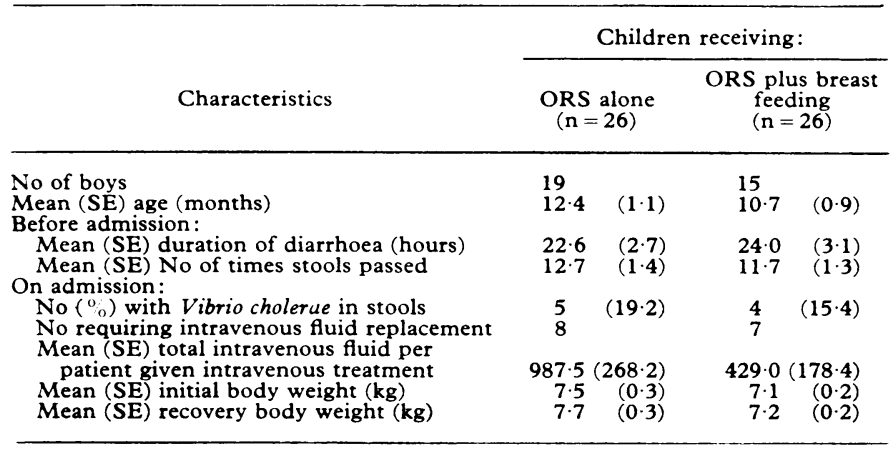

TABLE II-Clinical response by breast fed children with diarrhoea to either oral rehydration solution $(O R S)$ alone or $O R S$ and breast feeding. Figures are means ( $S E$ )

\begin{tabular}{|c|c|c|c|}
\hline \multirow[b]{2}{*}{ Response variable } & \multicolumn{2}{|c|}{ Children receiving: } & \multirow[b]{2}{*}{ Significance } \\
\hline & $\begin{array}{l}\text { ORS alone } \\
(\mathrm{n}=26)\end{array}$ & $\begin{array}{l}\text { ORS plus breast } \\
\text { feeding } \\
(\mathrm{n}=26)\end{array}$ & \\
\hline $\begin{array}{c}\text { Stool output: } \\
\text { ml/patient }\end{array}$ & $887 \cdot 4(116 \cdot 0)$ & $640.9 \quad(65 \cdot 5)$ & $\left\{\begin{array}{l}t=1 \cdot 8104 \\
\mathrm{NS}\end{array}\right.$ \\
\hline $\mathrm{ml} / \mathrm{kg} /$ patient & $115 \cdot 8 \quad(14 \cdot 5)$ & $89 \cdot 2(10 \cdot 0)$ & $\left\{\begin{array}{l}t=1 \cdot 5102 \\
\mathrm{NS}\end{array}\right.$ \\
\hline $\begin{array}{l}\text { No of times stools passed in } \\
\text { hospital }\end{array}$ & $17 \cdot 4 \quad(2 \cdot 3)$ & $12 \cdot 1 \quad(1 \cdot 1)$ & $\left\{\begin{array}{l}t=2.0396 \\
\mathrm{p}=0.05\end{array}\right.$ \\
\hline Vomitus volume ( $\mathrm{ml} /$ patient $)$ & $15 \cdot 2 \quad(8 \cdot 5)$ & $22.9 \quad(10 \cdot 9)$ & $\left\{\begin{array}{l}t=0.5571 \\
\mathrm{NS}\end{array}\right.$ \\
\hline $\begin{array}{l}\text { Duration of diarrhoea in } \\
\text { hospital (hours) }\end{array}$ & $45 \cdot 7 \quad(3 \cdot 9)$ & $43 \cdot 3 \quad(5 \cdot 0)$ & $\left\{\begin{array}{l}t=0.3785 \\
\text { NS }\end{array}\right.$ \\
\hline $\begin{array}{l}\text { Total ORS required for } \\
\text { rehydration (ml/patient) }\end{array}$ & $2119 \cdot 2(192 \cdot 1)$ & $1570.4(112.5)$ & $\left\{\begin{array}{l}t=2.4652 \\
\mathrm{p} \cdot 0.02\end{array}\right.$ \\
\hline
\end{tabular}

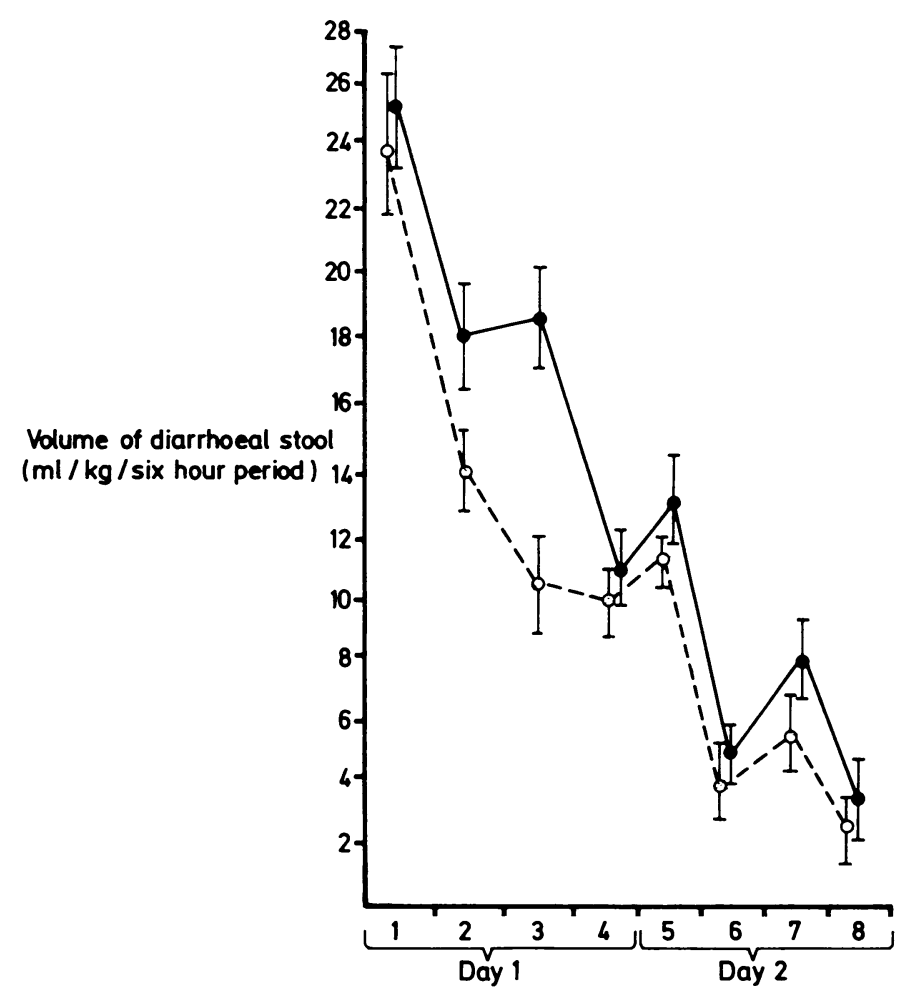

Changes in mean (SE) voiumes of diarrhoeal stuuls produced every six hours by children receiving either oral rehydration solution (ORS) alone $(-\infty-)$ or breast feeding plus ORS (- - O- -). Volumes measured on eight occasions at six hour intervals.

\section{Discussion}

Although breast feeding during diarrhoea has been advocated by many people, ${ }^{12}$ no controlled clinical trial to compare breast feeding plus oral rehydration solution with oral rehydration solution alone during the early phase of acute diarrhoea has previously been reported. The findings of the present study suggest that breast feeding during the early acute phase of diarrhoea does not exacerbate the clinical course of diarrhoea and that, in fact, for a lower intake of oral rehydration fluids a larger net absorption of fluids (and nutrients) can be achieved, an effect that may be helpful in obviating the potential risk of hypernatraemia reported in young children given oral rehydration solutions for the treatment of diarrhoea. ${ }^{7}$ Products of digestion of breast milk in the children's small intestines, such as amino acids, dipeptides, and hexoses, may also have enhanced the absorption of sodium (and water) ${ }^{8}$ thus reducing stool volume and the frequency of diarrhoeal stools. 
Other theoretical reasons for continuing breast feeding during diarrhoea also need to be considered. Short term deprivation of nutrients by withholding breast feeding during the early acute phase of diarrhoea is serious as a fasting child loses an estimated $1-2^{\circ}$ of his or her body weight daily even in the absence of fluid losses due to diarrhoea. ${ }^{9}$ Breast fed children with diarrhoea have been shown to average a total energy intake $35 \%$ greater and a protein intake $250^{\circ}$ o greater than children who are completely weaned. ${ }^{10}$ Thus breast feeding not only confers protection against infections including diarrhoea and provides a low cost, highly nutritious source of uncontaminated food but also minimises the reduction in energy and protein consumption during diarrhoea and, as found in this study, exerts a beneficial effect on the clinical course and outcome of acute diarrhoea by reducing the number (and volume) of diarrhoeal stools.

We thank Dr Aung Than Batu for his guidance and criticism and $\mathrm{Dr} \mathrm{Ba}$ Tun and the nursing staff of the paediatric wards of the Infectious Diseases Hospital for their help with the project. This project was supported in part by a clinical research grant from the Department of Medical Research.

\section{References}

1 World Health Organisation. Treatment and prevention of dehydration in diarrhoeal

2 World Health Organisation. Clinical management of acute diarrhoea. Diarrhoeal Diseases Control Programme. Report of a scientific working group. Geneva: WHO,

3 Chung AW. The effect of oral feeding at different levels on the absorption of food stuffs in infantile diarrhoea. $\mathcal{f}$ Pediatr $1948 ; 33: 1-13$.

. The early feeding versus early oral starvation on the course of infantile diarrhoea. I Pediatr $1948 ; 33: 14-22$.

Che course of infantile diarrhoca $f$ Pedialr 1948 ;33:14-22. cholera in children. Am f Clin Nutr 1981;34:1548-51.

Braun $\mathrm{OH}$, Sander A. Special milk formulas in the dietary treatment of diarrhoea in infants. Monatsschr Kinderheilkd 1981;129:467-71.

Cleary TG, Cleary KR, DuPont HL, et al. The relationship of oral rehydration solution to hypernatremia in infantile diarrhea. $\mathcal{F}$ Pediatr $1981 ; 99: 739-41$.

P SC, Mahalanas D, Jalan KN Sen A, Banerjee P. In search of a super olution: controlled trial of glycine-glucose oral rehydration solution in infantile diarrhoea. Acta Paediatr Scand 1984;73:18-21.

9 Rhode JE. Preparing for the next round: convalescent care after acute infection. Am 7 Clin Nutr 1978:31:2258-68.

10 Chen LC, Huq E, Huffman SL.A prospective study of the risk of the diarrhoeal diseases according to nutritional A prospective study of the risk of the diarrhoeal School of Public Health, Department of Population Sciences Report, 1980.

\title{
Effect of long term hormone replacement on plasma prolactin concentrations in women after oophorectomy
}

\author{
D H BARLOW， G H BEASTALL， H I ABDALLA，J ELIAS-JONES， R LINDSAY， D M HART
}

\begin{abstract}
Plasma prolactin concentrations were studied in 88 oophorectomised women who had been receiving mestranol or placebo for three to 11 years. Thirty one of them were also studied under basal conditions and by tests with thyrotrophin releasing hormone. Under basal conditions the mean prolactin concentration was higher in the oestrogen treated group but under nonrested, clinic conditions the difference was lost because of a rise in prolactin value in the placebo group only. Hence the groups showed a different prolactin response to the mild stress of clinic attendance but the same proportionate responsiveness to thyrotrophin releasing hormone.

The data suggest that long term hormone replacement has no significant effect on circulating prolactin concentrations under non-rested, everyday conditions and that the prolactin stimulating effects of minor stress and oestrogen may share a similar mechanism.
\end{abstract}

\section{Introduction}

A large number of women now receive oestrogen preparations on a long term basis. Oestrogen stimulates prolactin release in normal ${ }^{1}$ and hypogonadal women, ${ }^{2}$ probably by both hypothalamic dopamine suppression and direct action on the lactotroph. ${ }^{3}{ }^{4}$ There has been concern whether women receiving oestrogen preparations long term are at increased risk of developing prolactinoma or breast cancer. In relation to prolactinoma current evidence favours no increased risk in users of oral contraceptives, ${ }^{5}{ }^{6}$ though some workers have mooted such a risk. ${ }^{78}$

The question of a relation between use of oral contraceptives and breast cancer has been examined recently. ${ }^{9}$ Published work on postmenopausal use of oestrogen and the risk of breast cancer is contradictory, but current data do not suggest a significant increased risk. ${ }^{11}{ }^{11}$ There is a potential for oestrogen treatment to stimulate breast tissue by direct action and by virtue of a chronic increase in circulating prolactin concentrations. The role of prolactin in the induction of breast cancer remains ill defined, ${ }^{12} 13$ but there is evidence that prolactin promotes the development and growth of mammary tumours in rodents. ${ }^{14}$

There is limited information on the effect on plasma prolactin of menopausal oestrogen replacement therapy as used in clinical practice..$^{15} 16$ This study examines the effect of long term, low dose mestranol on plasma prolactin concentrations and responses to thyrotrophin releasing hormone in a large placebo controlled series originally set up to study oestrogen prophylaxis against postoophorectomy oesteoporosis. ${ }^{17}$

\section{Patients and methods}

All patients in the study had undergone hysterectomy and bilateral oophorectomy three months, three years, or six years before entry to the series. Allocation to treatment was randomised and patients took continuous oral mestranol $24 \mu \mathrm{g}$ daily (17-ethinyloestradiol-3- 